AperTO - Archivio Istituzionale Open Access dell'Università di Torino

\title{
Neutron scattering material analysis of Bronze Age metal artefacts
}

\section{This is the author's manuscript}

Original Citation:

Availability:

This version is available http://hdl.handle.net/2318/80041

since

Published version:

DOI:10.1088/0953-8984/20/10/104253

Terms of use:

Open Access

Anyone can freely access the full text of works made available as "Open Access". Works made available under a Creative Commons license can be used according to the terms and conditions of said license. Use of all other works requires consent of the right holder (author or publisher) if not exempted from copyright protection by the applicable law. 


\author{
R. ARLETTI ${ }^{1}$ \\ L. CARTECHINI ${ }^{2, \infty}$ \\ R. RINALDI ${ }^{3}$ \\ S. GIOVANNINI ${ }^{1}$ \\ W. KOCKELMANN ${ }^{4}$ \\ A. CARDARELLI ${ }^{1}$
}

\section{Texture analysis of bronze age axes by neutron diffraction}

\author{
${ }^{1}$ Dipartimento di Scienze della Terra, Università di Modena e Reggio Emilia, Modena, Italy \\ 2 ISTM-CNR, Perugia, Italy \\ ${ }^{3}$ Dipartimento di Scienze della Terra e Centro di Eccellenza SMAArt, Università di Perugia, Perugia, Italy \\ ${ }^{4}$ Rutherford Appleton Laboratory, ISIS Facility, Chilton, Didcot, UK
}

\begin{abstract}
Received: 8 November 2006/Accepted: 17 July 2007
Published online: 24 August 2007 • C) Springer-Verlag 2007

ABSTRACT Neutron diffraction has been utilised as a noninvasive diagnostic tool to gain insight into the ancient metallurgic and manufacturing techniques employed for the production of three bronze age axes from archaic to late bronze age (20th to 13th Century BC). The analysed bronze artefacts are from the "Terramare" and other bronze age settlements near Modena, Italy. Neutron diffraction provides the alloy and phase compositions in a totally non destructive approach, without interference from surface alteration and corrosion layers. Furthermore, neutron based texture analysis, with the advantage of large grain statistics deep into the bulk, provides details of the production techniques that can complement traditional metallographic examinations, and may provide unique information for samples that cannot suffer invasive treatments.
\end{abstract}

PACS 61.12.Ld; 81.05.Bx

\section{$1 \quad$ Introduction}

Scientific investigations of metallic archaeological materials are aimed at providing answers to complex questions regarding dating, ore provenance, metallurgic techniques, working treatment, state of conservation and others, mostly without a direct knowledge of the production site (unavailability of raw minerals and smelting slags). Thus most of the knowledge on ancient metal technology is provided by chemical and physical studies of the original artefacts. Xray fluorescence, $\mathrm{X}$-ray diffraction, and optical and electron microscopy are some of the most common techniques used for composition and structural characterization of metal artefacts $[1,2]$, mainly obtained by the analysis of micro-samples, although not representative of the whole object. In particular, the characterization of sample cross-sections by optical and electron microscopy allows deriving of local information on element distribution (metal composition and corrosion layers) as well as on metallography and the microstructure of the metal, thus providing clues to the manufacturing technique (casting, working process, and thermal treatment). In fact, inclusions, dimension of grains, segregation effects, twin

Fax:+39075 5855606, E-mail: laura@thch.unipg.it lines, strain lines, grain deformation, etc. represent fundamental observations for obtaining definite information on the metallurgic and manufacturing history of the objects [3].

When considering that these investigations in the field of the science of cultural heritage often involve unique samples, the principle that destructive sampling techniques should be avoided wherever possible ought to be applied, and the use of non-destructive analytical procedures should be considered. The intrinsic properties of neutrons make them an ideal probe for the study of materials and artefacts (ancient and modern) where non-destructiveness is of paramount importance $[4,5]$. In fact, the low attenuation of neutrons and high penetration power for most materials allows a bulk analysis of relatively large, intact and precious archaeological objects (probing $\mathrm{cm}^{3}$ volumes deep into the interior). Among neutron-based techniques, neutron diffraction stands out as a tool for quantitative phase and structural analysis of polycrystalline materials by means of the Rietveld method [6]. In particular this technique is remarkably suitable for the study of metal artefacts [7-9], having the additional advantage to provide for the characterization of micro-strains (i.e. crystallite deformation and distortion) and texture properties. These properties are directly correlated to the thermal and working treatments the object has undergone. A polycrystalline material is said to have a "texture" when crystallites are affected by preferred orientation, i.e. they are non-randomly oriented. This reflects on diffraction profiles showing different relative peak intensities when changing the sample orientation with respect to the incident probing beam and the detector [10]. Recently, systematic texture studies by neutron diffraction $[8,11]$ on laboratory bronze standards demonstrated that metal texture is peculiar to the specific working treatment. Hammered, rolled, and cast materials have typical texture fingerprints [12]; thermal treatment produces recrystallisation textures that, in general, depend on the previous mechanical working. Furthermore, plastic deformation of the metal and the corresponding texture fingerprint is usually combined with micro-strain effects that manifest themselves by diffraction peak broadening. However, there is no unequivocal relation between broadening and treatment because different working steps can yield similar degrees of broadening and thermal annealing can wipe out initial microstrain broadening. Moreover, broadening effects can be also ascribed to 
grain size and alloy heterogeneities. In practice it is difficult to distinguish between different sources of line broadening. Nevertheless, a line broadening analysis can provide key information on treatments, especially if data are compared to laboratory control samples or when comparing different samples in a series [13].

Following these considerations we have recently undertaken neutron diffraction investigations of bronze age artefacts from the Terramare and other settlements in the Po plains near Modena, Italy. These settlements represent one of the most advanced cultural, social and economic models of the bronze age in Italy and Europe [14] characterized by a specialized artisan production, mainly dedicated to metal manufacture. The study is aimed at obtaining information on the ancient metallurgic and manufacturing techniques developed by this culture. The work stems from a widely spanning research project including mineralogical studies on the provenance of raw materials used in bronze age metal production in Northern Italian settlements by means of conventional techniques (optical microscopy, scanning electron microscopy, and electron probe micro analysis) [15]. The results obtained by neutron diffraction are in reasonable agreement with those obtained by conventional invasive techniques thus fostering a wider use of the neutron method in archaeo-metallurgical studies. This work reports the study of additional microstructural data related to the presence of microstrain and crystallographic texture, mostly resulting from thermal and mechanical treatments during fabrication and/or daily use of the tools. For one of the samples we could compare the neutron diffraction results with the information provided by traditional invasive metallographic analysis [15].
2

\section{Analysed samples}

The present neutron diffraction investigation involves three bronze axes from the early to the late bronze age: Savignano 994 (XX c. BC), Montale 1 (XVI-XV c. BC) and Formigine 2452 (XIII c. BC). The two oldest axes (Savignano 994 and Montale 1) have prominent rims on the four edges of the body, whereas Formigine 2452 is a 'flanged axe' having extended and curved rims at the mid point of the body (see Fig. 1a-c). Alloy composition, phase abundance and microstructural information were obtained on the basis of neutron diffraction measurements at the ROTAX and GEM beam lines of the neutron spallation source ISIS at the Rutherford Appleton Laboratory, UK [16]. Experimental data were treated by Rietveld refinement by means of the GSAS package [17] with the EXPGUI [18] interface. The quantitative phase analysis showed differences in alloy compositions thus suggesting changes with time in both raw materials and metallurgic technology. The determination of the composition provided average tin percentages of $1.7,6.8$, and 4.4 ( \pm 0.5 wt. \%) respectively for the Savignano 994, Montale 1 and Formigine 2452 samples. A slight increase in Sn content from the edge to the body of the axes was observed, probably due to segregation effects caused by temperature gradients during alloy cooling. Bronze peak broadening effects (larger at the edge and smaller at the body) were estimated by Rietveld refinement and provided important information for the study of texture and micro-strain properties of the materials (see the following sections). Lead inclusions were observed in amounts of about 1 and $2 \mathrm{wt}$ \% respectively for the axes from the Middle and the Recent bronze age;

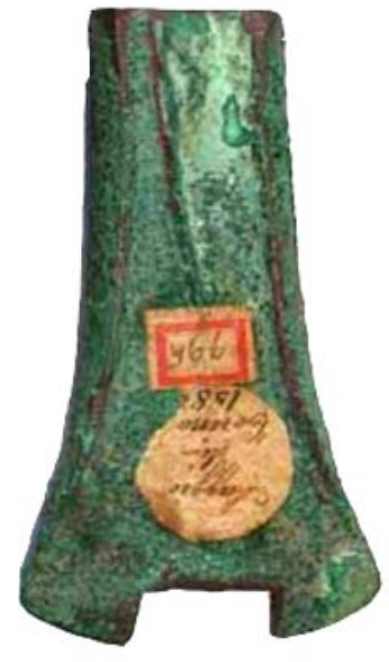

a

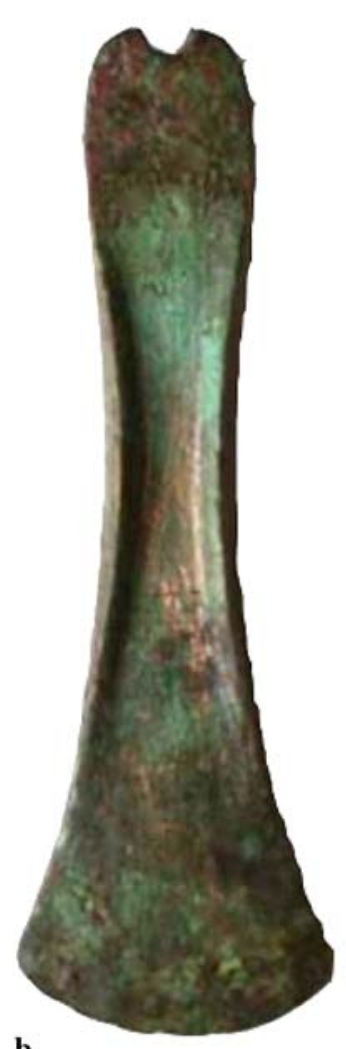

b

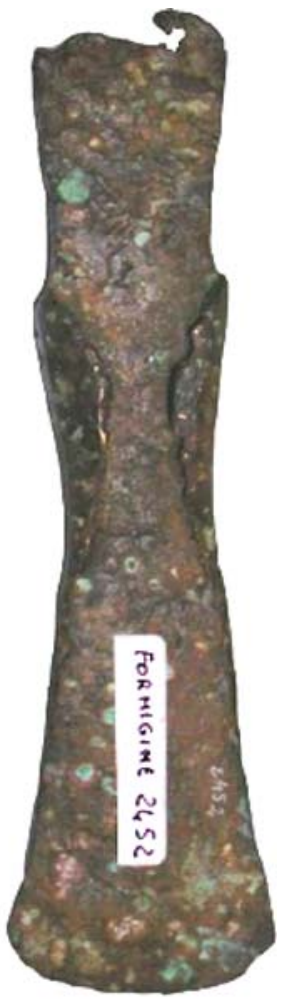

c
FIGURE 1 Photos of samples (a) Savignano 994 (XX c. BC), (b) Montale 1 (XVI-XV c. BC) and (c) Formigine 2452 (XIII c. BC) (by courtesy of the Museo Civico Archeologico Etnologico di Modena) 
two different explanations may account for the presence of $\mathrm{Pb}$ : it may be an impurity or it was used intentionally as a low-melting agent. Traces of chalcocite were found in the middle bronze age axe which may hint towards the use of sulphide copper minerals as a raw starting material to produce bronze. Moreover, the observation of mineral phases typical of bronze corrosion (cuprite, malachite, and nantokite) allowed an evaluation of the state of conservation of the materials.

\section{$3 \quad$ Experimental}

Neutron diffraction data for texture analysis were collected at the GEM beamline from the body and from the edge of the three axes in order to identify any variation in texture properties that may point to different working treatment and use of the two parts. A detailed description of the experimental set up has been already reported [16]. The GEM beamline uses a polychromatic neutron beam to carry out time of flight (ToF) measurements by means of a multi-bank detector set-up yielding the simultaneous collection of complete diffraction patterns over a large range of angles [19,20]. The redundant diffraction information from a multitude of detector elements provides remarkably robust Rietveld refinements for the analysis of structural details. A further advantage deriving from the combination of the ToF technique with the use of a multi element detector set up is the possibility of deriving information on the crystallographic texture from change in Bragg intensities for different sample "orientations". In fact, each detector element at a given angle collects diffraction data from a distinct sample/detector/beam orientation providing information on the orientation of crystallites in the sample fulfilling Bragg's law for that particular detector element. Moreover, due to the polychromatic nature of the neutron beam, each detector element simultaneously observes many Bragg peaks (i.e. lattice planes), thus containing more orientation information in the form of relative intensities. This is why the number of sample orientations necessary to determine the texture is typically small on a ToF diffractometer. Thanks to the large, almost 3D detector coverage on GEM, the crystallographic texture can be obtained even in a single, stationary measurement [20]. For this reason it has been possible to use the data collected on GEM to carry out a full texture analysis of the axes, providing the full orientation distribution function (ODF) [10].

Even though a single sample orientation is sufficient for reconstruction of the crystallite orientations, we chose to collect data for two sample orientations in order to facilitate the correction for absorption of scattered neutrons in the bulky objects. Each axe was suspended in an aluminium foil pocket and mounted in the GEM sample chamber in a vertical orientation (long side of the axe mounted upright, perpendicular to the incident beam). After collection of a first data set, the axe was re-oriented and rotated by 60 degrees with respect to the incoming beam direction for a second data collection. Figure 2 illustrates the corresponding pole figure coverage on GEM [20] and the reference system in the standard metallurgical convention in terms of normal (ND), rolling (RD) and transverse (TD) directions. The data acquisition time was 15 min per orientation. After data reduction a total of 320
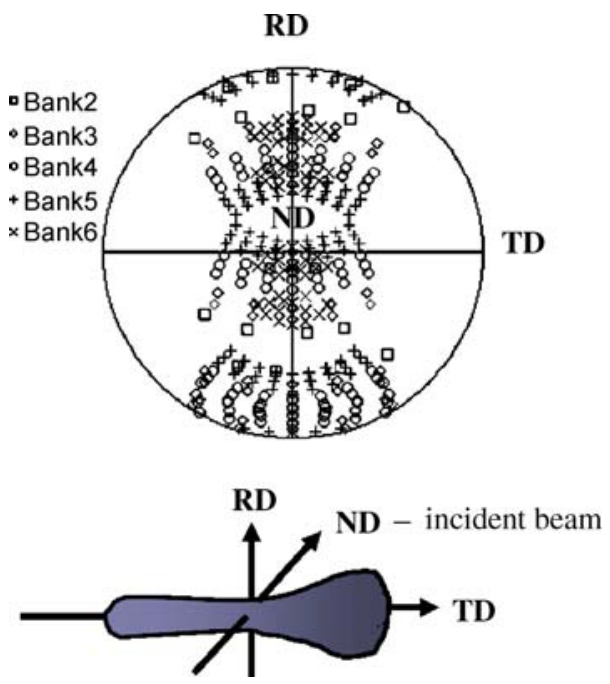

FIGURE 2 Pole figure coverage and reference system for the neutron texture analyses on GEM, indicating the "normal direction" (ND), the "rolling direction" (RD) and the "transverse direction" (TD). Pole densities in the center along ND, for instance, indicate directions normal to the blade of the axes, while pole densities on the top of the pole figure (RD) represent directions along the short side of the axes

diffraction patterns for the two sample settings were obtained, representing as many orientations. The size of the neutron beam was $10 \times 10 \mathrm{~mm}^{2}$.

The full orientation distribution functions (ODF) have been reconstructed from the experimental data by Rietveld refinement of the 320 data sets by means of the program MAUD [21] using the so-called EWIMV algorithm [22]. Texture analysis results are presented in the form of "pole figures" representing the $2 \mathrm{D}$ projections of the orientation distribution of specific $h k l$ lattice planes (the pole is the normal direction to the crystal plane). In principle, a pole figure for each observed Bragg peak can be plotted. In practice, it is customary to present the texture by the pole figures of the main crystallographic directions $\langle 111\rangle,\langle 200\rangle$, and $\langle 220\rangle$ of the face centered cubic crystal system of copper and bronze. Each point in the pole figure corresponds to a particular orientation. For instance, for the three samples the normal direction to the plane of the tools corresponds to the center of the pole figure. Figures 3 and 4 display the pole figures reconstructed by the MAUD analysis. The colour scale represents pole densities in multiples of random distribution (mrd) units. Densities are normalized with respect to the average (random) distribution; thus a one-colour pole figure showing uniform density of $1.0 \mathrm{mrd}$ would indicate the absence of texture.

To support the interpretation of texture results, complementary information on micro-strain effects have been considered on the basis of the peak broadening analysis of the diffraction profiles. A quantification of line broadening can be achieved in terms of the $\gamma_{1}$ parameter obtained from Rietveld analysis assuming a Lorentzian function and ignoring grain size effects. In order to avoid the line broadening contribution from sample thickness, the $\gamma_{1}$ parameter has been derived only for the diffraction profiles collected in the backward scattering direction. The so-called micro-strain parameter is then calculated from $\varepsilon_{\gamma}=\gamma_{1} / C \cdot 100 \%$, where $C$ is a diffractometer constant ( $C=9072.33$ for GEM-bank 6) [17]. 

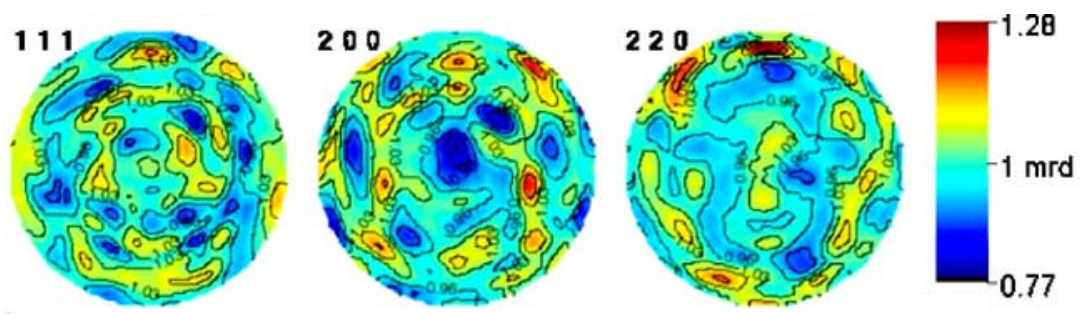

FIGURE 3 (111), (200), and (220) pole figures obtained from diffraction data collected on the body for (a) Savignano 994 (XX c. BC), (b) Montale 1 (XVIXV c. BC) and (c) Formigine 2452 (XIII c. BC) respectively

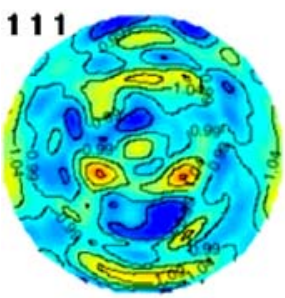

b
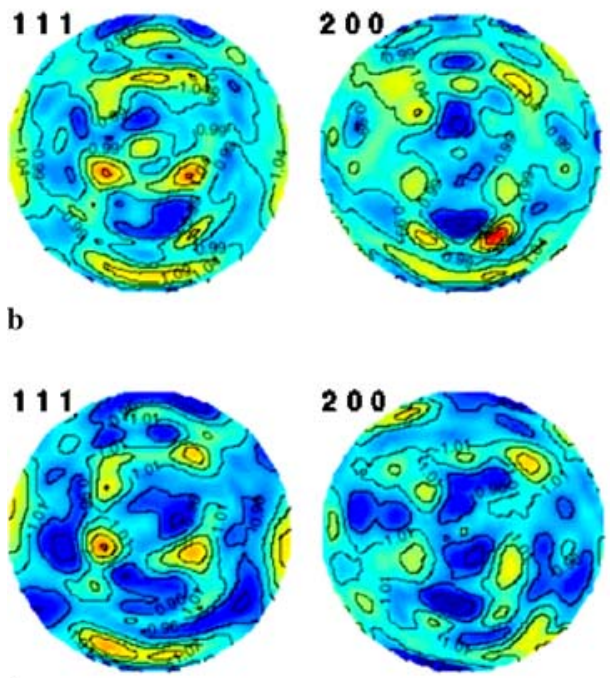

220
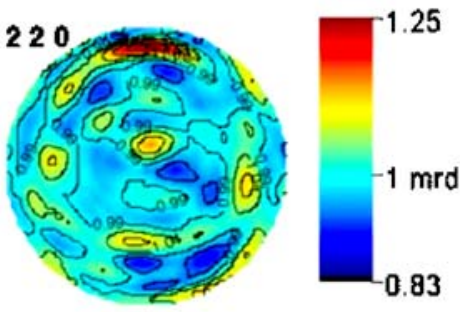

.83
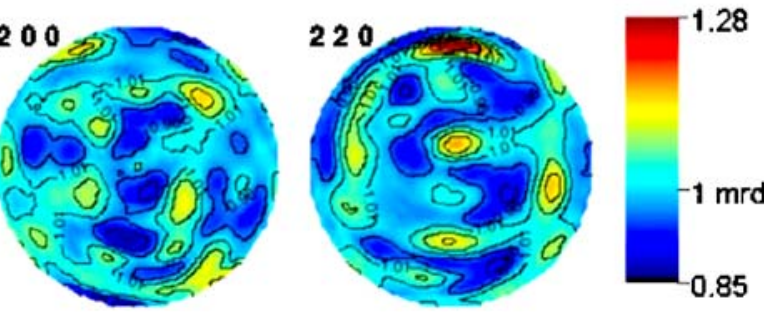

c

4

\section{Results and discussion}

Pole figures (111), (200), and (220) obtained from diffraction data collected on the body and the cutting edge are shown in Figs. 3 and 4. The three axes show remarkably weak textures both on the cutting edge and in the main body, with maximum pole densities at about $1.3 \mathrm{mrd}$ and minimum densities of $0.8-0.9 \mathrm{mrd}$. This means that only approx. $15 \%$ of the probed material "participates" in the non-random grain distribution. Any interpretation of the texture information has to take into account these very small deviations from randomness. However, it is possible to summarize some general observations.

- The body grain orientations show a rather irregular distribution, especially in the case of the Savignano 994 sample. Pole figures of the other two samples are very similar in appearance and are characterised by more regular densities, as confirmed by the inverse pole figures (not shown). The increased densities near the center of the (220) pole figures of all three axes are reminiscent of either a "goss" "hardening" texture component or a "brass" recrystallization component. [23]

- The cutting edge pole figures have more pronounced regular orientation distributions with distinct texture characteristics. The texture of the Savignagno 994 cutting edge is similar in appearance albeit slightly different in scale as compared with the corresponding bulk texture with a maximum in the center of the (220) pole figure, hinting towards the possible occurrence of goss and/or brass components [23]. The cutting edges of Montale 1 and Formigine 2452 show uniaxial and biaxial texture pat- terns, respectively, the latter likely being due to directional mechanical working along the blade.

Despite the weak textures, it is evident that the Savignano axe, dating to an earlier period, was worked differently than the later Montale and Formigine axes. This is confirmed by the microstrain analysis [16]: The Savignano axe exhibits similar microstrain broadening for bulk $\left(\varepsilon_{\gamma}=0.06 \%\right)$ and edge $\left(\varepsilon_{\gamma}=0.11 \%\right)$. These results indicate that the axe was probably worked only for shaping and not for hardening. The middle and recent bronze age axes however, display distinct microstrain broadening on the cutting edges $\left(\varepsilon_{\gamma}=0.43 \%\right.$, $\left.\varepsilon_{\gamma}=0.34 \%\right)$ compared to the bulk ( $\left.\varepsilon_{\gamma}=0.17 \%, 0.09 \%\right)$, indicating a deliberate hardening by cold working. The regular appearance of the diffraction peaks and pole figures suggests the application of alternate annealing and working cycles. It has to be noted that microstrain broadening cannot be distinguished from diffraction peak broadening due to tin content variation. However, it can be assumed that the edges have undergone more mechanical work than the bulk, so that the broadening could be considered more an indicator of the hardening process (microstrains) rather than of the casting process (compositional broadening).

The absence of a considerable texture indicates that the axes have neither been strongly worked nor extensively heat treated. Recrystallisation is less pronounced than observed in eneolithic copper axes from Northern Italy [24]. This may reflect the general view that materials with low stacking fault energies, such as bronze, generally exhibit much weaker recrystallisation textures than materials with high stacking fault energies like copper [23]. 


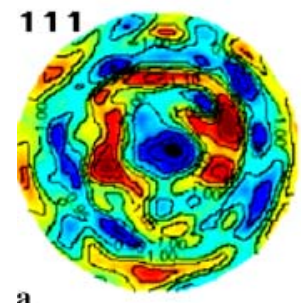

a

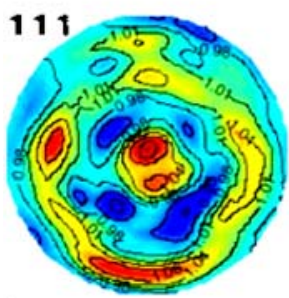

b

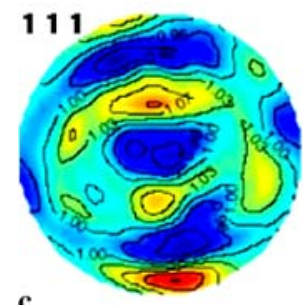

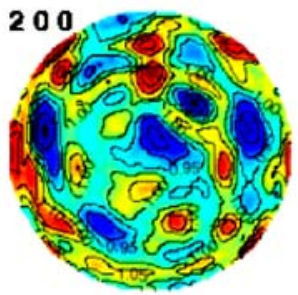
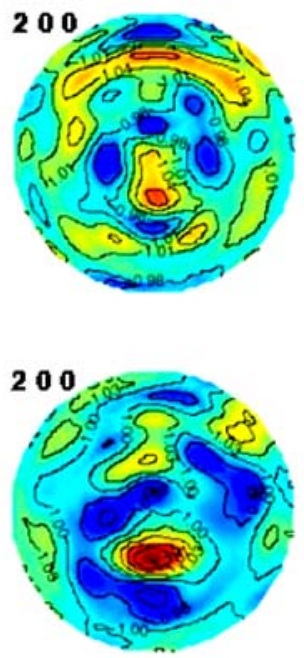
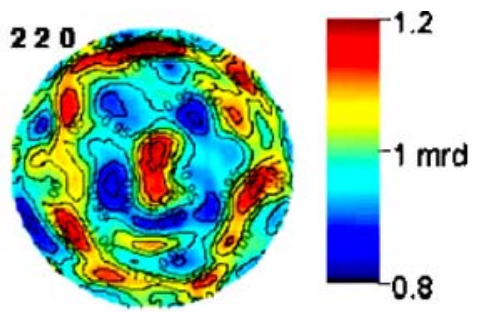

FIGURE 4 (111), (200) and (220) pole figures obtained from diffraction data collected on the cutting edge for (a) Savignano 994 (XX c. BC), (b) Montale 1 (XVI-XV c. BC) and (c) Formigine 2452 (XIII c. BC) respectively
In the case of the Savignano 994 sample, we had the opportunity of comparing our texture analysis with traditional invasive metallography on an exposed inner section of the axe central body carried out at an earlier date [15]. In Fig. 5 the photomicrograph (x80) of the alloy body after cutting, polishing and etching with ferric chloride solution is shown. Regular twinned grains are typical for recrystallisation without apparent effects from mechanical treatments, as inferred from the interpretation of the pole figures obtained from the neutron diffraction experiments. The metallographic analysis in a more external area of the same section (not investigated in

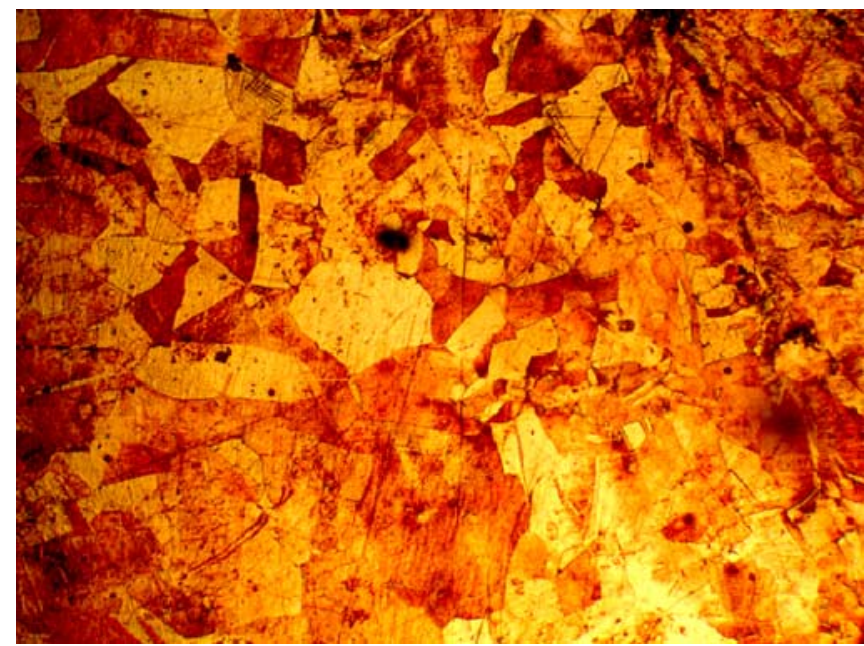

FIGURE 5 Photomicrograph (x80) of the body of the Savignano 994 sample showing a regular grain distribution characterized by twin lines typical of recrystallisation the present texture study) shows grains having smaller dimensions and less regular shape that, combined with the presence of slip lines, suggest the local application of a moderate mechanical treatment. This observation supports the texture results on the Savignano 994 axe for which we exclude intensive hardening treatments. As a matter of fact other metallographic investigations on axes of similar composition and having the same pertinence of the samples studied in the present work evidenced typical microstructures reflecting a higher degree of mechanical treatment.

\section{$5 \quad$ Conclusions}

Neutron diffraction analysis provides average information on the composition and working treatments of bronze artefacts. The interpretation of microstrain broadening and preferred orientation of crystallites with regard to working techniques is not unambiguous and may have to be supported by conventional metallography. Hence, neutron diffraction provides information in a truly non destructive mode which can be used in conjunction with information from traditional metallographic analysis when the latter can be obtained on the same or a similar artefact. If sampling of an artefact is permitted, then the metallographic examination of a single spot may be used to "calibrate" the neutron diffraction results in terms of deformation strength and hardness; the neutron diffraction technique can then be used to survey the whole object or a whole class of similar objects non-destructively. If sampling is not permitted, the metallographic calibration can be attempted on the basis of laboratory replica objects in order to achieve a quantitative interpretation of neutron texture results. 
ACKNOWLEDGEMENTS Financial support to R.R. is acknowledged from MIUR (Italian Ministry of University and Research) for Grant No. 2004041033-4 (PRIN). The Italian National Research Council (CNR) is acknowledged for access to the ISIS Facility (UK) through the mutual Agreement (No. 01/9001) between CNR and the CCLRC. The Museo Civico Archeologico Etnologico di Modena is also acknowledged for making this study possible.

\section{REFERENCES}

1 E. Ciliberto, G. Spoto, Modern Analytical Methods in Art and Archaeology (Wiley, New York, 2000)

2 D.A. Scott, J. Podany, B. Considine, Ancient and Historic Metals - Conservation and Scientific Research (Getty Conservation Institute, 1994)

3 D.A. Scott, Metallography and Microstructure of Ancient and Historic Metals (Getty Conservation Institute, Los Angeles, 1991)

4 E. Deschler-Erb, E.H. Lehmann, L. Pernet, P. Vontobel, S. Hartmann, Archaeometry 46, 647 (2004)

5 W. Kockelmann, E. Pantos, A. Kirfel, in Radiation in Art and Archae ometry, ed. by D.C. Creagh, D.A. Bradley (Elsevier, Amsterdam, 2000), pp. 347-377

6 R.A. Young, The Rietveld method (Int. Union Crystallog., Oxford University Press, 1993)

7 W. Kockelmann, S. Siano, M. Schreiner, Studio e Conservazione di Manufatti Archeologico (Nardine Editore, Firenze, 2004), pp. 431-451

8 W. Kockelmann, S. Siano, L. Bartoli, D. Visser, P. Hallebeek, R. Traum, R. Linke, M. Schreiner, A. Kirfel, Appl. Phys. A 83, 175 (2006)

9 L. Cartechini, R. Rinaldi, W. Kockelmann, S. Bonamore, D. Manconi, I. Borgia, P. Rocchi, B.G. Brunetti, A. Sgamenllotti, Appl. Phys. A 83, 631 (2006)

10 H.-R. Wenk, P. Van Houtte, Rep. Prog. Phys. 67, 1367 (2004)
11 S. Siano, L. Bartoli, L.R. Santisteban, W. Kockelmann, M.R. Daymond, M. Miccio, G. De Marinis, Archaeometry 48, 77 (2006)

12 X. Yanxia, L. Lutterotti, H.R. Wenk, F. Kovacs, J. Mater. Sci. 39, 3329 (2004)

13 S. Siano, L. Bartoli, M. Zoppi, W. Kockelmann, M. Daymond, J.A. Dann, M.G. Garagnani, M. Miccio, Proc. Archaeometall. Eur. 2, 319 (2003)

14 G.L. Carancini, Le Terramare: La più antica civiltà Padana, ed. by M. Bernabò Brea, A. Cardarelli, M. Cremaschi (Electa, Milano, 1997), pp. $379-404$

15 S. Giovannini, PhD Thesis, University of Modena and Reggio Emilia (2006)

16 R. Arletti, L. Cartechini, S. Giovannini, R. Rinaldi, W. Kockelmann, A. Cardarelli, Nuovo Cim. C 30, 11 (2007)

17 A.C. Larson, R.B. Von Dreele, GSAS: General Structure Analysis System Report, LAUR 86-748 (Los Alamos National Laboratories, USA, 1986), http://www.ccp14.ac.uk

18 B.H. Toby, J. Appl. Cryst. 34, 210 (2001)

19 P. Day, J.E. Enderby, W.G. Williams, L.C. Chapon, A.C. Hannon, P.G. Radaelli, A.K. Soper, Neutron News 15, 19 (2004)

20 W. Kockelmann, L.C. Chapon, P.G. Radaelli, Physica B 385-386, 639 (2006)

21 L. Lutterotti, MAUD, material analysis using diffraction (www.ing.unitn.it/ luttero/maud/index.html)

22 S. Matthies, G.W. Vinel, Phys. Stat. Solidi B 112, K111 (1982)

23 U.F. Kocks, C.N. Tomé, H.-R. Wenk, Texture and Anisotropy (University Press, Cambridge, 1998)

24 G. Artioli, M. Dugnani, T. Hansen, L. Lutterotti, A. Pedrotti, G. Sperl, La mummia dell'età del rame. 2. Nuove ricerche sull'uomo venuto dal ghiaccio ed. by A. Fleckinger (Folio Verlag, Bolzano, 2003) Vol. 3, pp. 9-22 